\title{
ANALISIS PEMANTAPAN MUTU INTERNAL PEMERIKSAAN TROMBOSIT DI INSTALASI LABORATORIUM RSUD SULTAN IMANUDDIN PANGKALAN BUN
}

\author{
${ }^{1}$ Risa Wahyuningsih \\ ${ }^{1}$ Stikes Borneo Cendekia Medika Pangkalan Bun \\ ${ }^{1}$ Email: risa.analisbcm16@yahoo.com
}

\begin{abstract}
ABSTRAK
Hasil pemeriksaan laboratorium harus terjamin mutunya. Pemantapan mutu internal trombosit dilakukan secara mandiri oleh laboratorium klinik dengan memonitor prosedur pemeriksaan yang merupakan indikator kinerja laboratorium sehingga mutu akurasi (ketepatan) dan presisi (ketelitian) hasil laboratorium dapat terus ditingkatkan. Tujuan pemantapan mutu internal adalah mengendalikan hasil pemeriksaan laboratorium setiap hari dan untuk mengetahui penyimpangan hasil laboratorium untuk segera diperbaiki. Jenis penelitian ini adalah deskriptif, untuk mengetahui dan menganalisis pemantapan mutu internal pemeriksaan trombosit di Instalasi Patologi klinik RSUD Sultan Imanuddin, yang meliputi tahap pra analitik, analitik, dan pasca analitik. Subyek penelitian Subjek dalam penelitian ini adalah seluruh petugas labotarorium yang terlibat langsung pada proses pemeriksaan trombosit. Responden ditetapkan secara purposive karena mempertimbangkan kekayaan informasi, kemampuan serta kewenangan subyek penelitian. Sehingga diharapkan peneliti akan mendapatkan informasi yang sebanyak - banyaknya tentang pelaksanaan pemantapan mutu pemeriksaan trombosit. Peneliti sebagai instrumen penelitian dalam hal ini melakukan observasi terhadap pelaksanaan pemantapan mutu internal mulai tahap pra analitik, analitik dan paska analitik. Peneliti melakukan wawancara terhadap petugas dan penanggung jawab laboratorium klinik RSUD Sultan Imanuddin. Sebagai alat bantu, peneliti menggunakan tape rekorder untuk merekam wawancara, kamera untuk mengabadikan kegiatan , alat tulis, pedoman wawancara dan check list sebagai panduan observasi. Hasil pelaksanaan pemantapan mutu internal untuk pemeriksaan darah lengkap otomatis di Instalasi Patologi Klinik RSUD Sultan Imanuddin Pangkalan Bun yaitu : Tahap pra analitik mencapai 75,8\% masuk dalam kriteria baik ; Tahap analitik mencapai $76,4 \%$ masuk dalam kriteria kurang baik; Tahap pasca analitik mencapai 69,2\% masuk dalam kriteria kurang baik. Hasil uji ketepatan, ketelitian, dan sigma metri untuk pemeriksaan trombosit yaitu : ketepatan pemeriksaan trombosit di Instalasi Laboratorium RSUD Sultan Imanuddin kurang baik menurut acuan Ricos Database ; ketelitian pemeriksaan trombosit di Instalasi Laboratorium RSUD Sultan Imanuddin kurang baik menurut acuan Ricos Database.
\end{abstract}

Kata Kunci : Analisis, Pemantapan Mutu Internal, Trombosit, Laboratorim.

\author{
ANALYSIS OF INTERNAL QUALITY CONSOLIDATION INSPECTION \\ TROMBOSIT IN LABORATORY INSTALLATION OF SULTAN IMANUDDIN \\ PANGKALAN BUN HOSPITAL
}




\begin{abstract}
ABSTRACK
Laboratory results must be guaranteed quality. Internal platelet quality stabilization is carried out independently by the clinical laboratory by monitoring the examination procedures which are indicators of laboratory performance so that the quality of accuracy (accuracy) and precision (accuracy) of laboratory results can be continuously improved. The purpose of strengthening internal quality is to control the results of laboratory examinations every day and to find out the deviation of laboratory results to be corrected immediately. This type of research is descriptive, to determine and analyze the internal quality of platelet examination in the Pathology Installation of Sultan Imanuddin Hospital, which includes pre-analytical, analytic, and post-analytic stages. Research Subjects The subjects in this study were all laboratory staff who were directly involved in the platelet examination process. Respondents were determined purposively because they considered the wealth of information, abilities and authority of the research subjects. It is hoped that researchers will get as much information as possible about the implementation of the quality of platelet examination. Researchers as research instruments in this case observe the implementation of internal quality stabilization starting from the pre-analytic, analytic and post-analytic stages. Researchers conducted interviews with officers and personnel in charge of the Sultan Imanuddin Regional Hospital clinical laboratory. As a tool, researchers use a tape recorder to record interviews, cameras to capture activities, stationery, interview guides and check lists as observation guides. The results of the implementation of internal quality consolidation for automated complete blood tests at the Clinical Pathology Installation of Sultan Imanuddin Pangkalan Bun Regional Hospital are: The pre-analytic stage reached $75.8 \%$, which included in the good criteria; The analytical phase reached $76.4 \%$ included in the unfavorable criteria; The post-analytical stage reached $69.2 \%$, which was included in the unfavorable criteria. The results of the accuracy, accuracy, and sigma metri test for platelet examination are: the accuracy of platelet examination in the Laboratory Installation of Sultan Imanuddin Hospital is not good according to the Ricos Database reference; the accuracy of platelet examination in the Sultan Imanuddin Regional Hospital Laboratory Installation is not good according to the Ricos Database reference.
\end{abstract}

Keywords: Analysis, Internal Quality Strengthening, Platelets, Laboratories

PENDAHULUAN

Rumah Sakit Umum Daerah

(RSUD) Sultan Imanuddin adalah

Rumah Sakit tipe B Non Pendidikan

dengan fungsi utama untuk

memberikan pelayanan kesehatan

kepada seluruh penduduk Kabupaten

Kotawaringin Barat, pada semua umur dan pada semua tingkat sosial masyarakat (RSPS, 2010). RSUD Sultan Imanuddin mempunyai visi “Terwujudnya rumah sakit yang unggul dan menjadi pilihan utama masyarakat Kotawaringin Barat dan sekitarnya" dan dengan motto "Kepuasan anda adalah kebahagiaan 
kami”. Sesuai dengan visi dan motto tersebut maka RSUD RSUD Sultan Imanuddin senantiasa melakukan perbaikan dan peningkatan mutu pelayanan kesehatan (RSPS, 2010).

Semakin tinggi tingkat pendidikan dan kesejahteraan masyarakat, akan mendorong meningkatnya tuntutan masyarakat terhadap mutu pelayanan kesehatan, Di pihak lain pelayanan Rumah Sakit yang memadai, baik di bidang diagnostik maupun pengobatan akan semakin dibutuhkan (RSPS, 2010)

RSUD Sultan Imanuddin memiliki Instalasi Laboratorium di bidang Patologi Klinik dan Patologi Anatomi, Bidang Patologi Klinik meliputi pelayanan Hematologi Klinik, Kimia Klinik, Immunologi, Laboratorium Penyakit Infeksi dan Bank Darah (RSPS, 2010). Sebagai bagian integral dari pelayanan kesehatan rumah sakit, Instalasi laboratorium Patologi Klinik RS Sultan Imanuddin juga dituntut untuk memberikan pelayanan dalam pelaksanaan berbagai program dan upaya kesehatan baik untuk keperluan penegakan diagnosis, pemberian pengobatan, evaluasi dan pemantauan terapi dan menentukan prognosis serta pengambilan keputusan klinik lainnya.
Laboratorium klinik adalah sarana kesehatan yang melaksanakan pengukuran, penetapan dan pengujian terhadap bahan dari manusia untuk menentukan jenis penyakit, kondisi kesehatan atau faktor yang dapat berpengaruh pada kondisi kesehatan perorangan dan masyarakat. Pengukuran dan pemeriksaan laboratorium akan menghasilkan data ilmiah yang penting dalam menghadapi masalah yang diidentifikasi melalui pemeriksaan klinis yang merupakan bagian esensial dari data pokok pasien (Sukorini, 2010).

Laboratorium
memberikan kontribusi $\begin{aligned} & \text { dalam } \\ & \text { penegakkan diagnosis } \\ & \text { dengan memberikan informasi } \\ & \text { obyektif dari status kesehatan seorang } \\ & \text { penderita dimana produk yang } \\ & \text { dihasilkan adalah analisis dan hasil } \\ & \text { pemeriksaan sampel penderita sebagai } \\ & \text { informasi medis yang obyektif } \\ & \text { (Budiono, 2011) } \\ & \text { Menurut Purwanto (dalam } \\ & \text { Budiono, 2011) idealnya pemeriksaan } \\ & \text { laboratorium harus teliti, tepat, } \\ & \text { spesifik, sensitif, cepat dan tidak } \\ & \text { mahal serta dapat membedakan pasien } \\ & \text { dengan orang normal. Para klinisi } \\ & \text { maupun pasien mengharapkan hasil } \\ & \text { pemeriksaan yang benar-benar }\end{aligned}$


terjamin mutunya. Mutu pemeriksaan merupakan target dari setiap proses dalam prosedur kontrol kualitas. Proses yang dilalui dapat dibagi menjadi pra analitik, analitik dan pascaanalitik dan hal ini juga dipengaruhi oleh bahan, alat, metode, sumber daya manusia, pasien, dan halhal lain yang terkait.

Undang Undang No. 23/1992 tentang kesehatan merupakan landasan hukum dalam pelaksanaan peningkatan mutu pelayanan kesehatan. Sebagai penjabaran dari Undang Undang tersebut salah satunya adalah Keputusan Menteri Kesehatan Republik Indonesia Nomor : 364/MENKES/III/2003 yang menyatakan dalam menyelenggarakan pelayanan laboratorium berkewajiban untuk menyediakan pelayanan laboratorium secara professional dan menjaga mutu pelayanan laboratorium serta menyelenggarakan Pemantapan Mutu Internal (PMI) dan mengikuti kegiatan Pemantapan Mutu Eksternal (PME) yang diakui oleh pemerintah bekerjasama dengan organisasi profesi (Dep Kes, 2004).

\section{METODOLOGI PENELITIAN}

Jenis penelitian ini adalah deskriptif, untuk mengetahui dan menganalisis pemantapan mutu internal pemeriksaan trombosit di Instalasi Patologi klinik RSUD Sultan Imanuddin, yang meliputi tahap pra analitik, analitik, dan pasca analitik. Penelitian ini dilakukan di laboratorium klinik RSUD Sultan Imanuddin, Kotawaringin Barat. RSUD Sultan Imanuddin merupakan satu-satunya rumah Sakit pemerintah kabupaten Kotawaringin Barat yang menyediakan tempat pendidikan dan penelitian.

Subjek dalam penelitian ini adalah seluruh petugas labotarorium yang terlibat langsung pada proses pemeriksaan trombosit. Responden ditetapkan secara purposive karena mempertimbangkan kekayaan informasi, kemampuan serta kewenangan subyek penelitian. Sehingga diharapkan peneliti akan mendapatkan informasi yang sebanyak - banyaknya tentang pelaksanaan pemantapan mutu pemeriksaan trombosit.

\section{HASIL}

Pelaksanaan penelitian pemantapan mutu internal pemeriksaan trombosit di Instalasi laboratorium klinik RSUD Sultan Imanuddin , dilakukan pada kunjungan pasien rawat jalan selama bulan November-Desember 2011. 
Observasi dilakukan pada tiga tahapan pemeriksaan yaitu tahap pra analitik, analitik dan pasca analitik.

Jumlah tenaga yang bekerja di Instalasi Laboratorium klinik RSUD Sultan Imanuddin sebanyak 30 orang. Terbagi ke dalam beberapa bagian yaitu pengambilan spesimen, pelayanan hematologi, pelayanan kimia klinik, dan pelayanan imunologi.

Instalasi Laboratorium
klinik RSUD Sultan Imanuddin
dalam menjalankan kegiatannya
sudah mengikuti standar prosedur
operasional yang telah ditetapakan.
Standar prosedur operasional yang
dimiliki oleh Laboratorium klinik
RSUD Sultan Imanuddin antara
lain meliputi: standar prosedur
operasional pengambilan dan
pengumpulan spesimen,
penanganan bahan infeksius,

pengambilan dan pemakaian reagen, penggunaan peralatan, kalibrasi alat, pemeliharaan peralatan, pemeriksaan, pelaporan dan arsip. Pada dasarnya setiap aktivitas yang ada di laboratorium harus memiliki pedoman baku yang mendukungnya, dari sistem mutu (normatif dan kebijakan) secara keseluruhan sampai pada proses paling teknis seperti cara memperoleh air untuk di analisa yang baik atau pemeliharaan suhu lemari es dan lain-lain (Depkes, 2010)

Wawancara dilakukan untuk menggali informasi yang lebih dalam tentang pelaksanaan pemantapan mutu internal. Wawancara dilakukan terhadap 6 orang responden dengan karakteristik seperti ditunjukkan dalam tabel.

Tabel 1. Karakteristik Responden

\begin{tabular}{ccccccc}
\hline No & $\begin{array}{c}\text { Usia } \\
\text { (Tahun) }\end{array}$ & $\begin{array}{c}\text { Jenis } \\
\text { kelamin }\end{array}$ & Pendidikan & $\begin{array}{c}\text { Masa kerja } \\
\text { (tahun) }\end{array}$ & Jabatan & $\begin{array}{c}\text { Kode } \\
\text { Responden }\end{array}$ \\
\hline 1 & 50 & P & DSPK & 23 & Ka. IPK & R1 \\
2 & 42 & L & D-IV Analis & 15 & Koord.IPK & R2 \\
3 & 25 & P & D-III Analis & 5 & PJ & R3 \\
4 & 26 & P & D-III Analis & 3 & AP & R4 \\
5 & 24 & P & D-III Analis & 1 & AP & R5 \\
6 & 23 & P & D-III Analis & 3 & AP & R6 \\
\hline
\end{tabular}

Sumber: Data primer Terolah, 2016 
Keterangan:

Ka. IPK

Koord. IPK

PJ

AP
: Kepala Instalasi Patologi Klinik

: Koordinator Instalasi Patologi Klinik

: Penanggung Jawab Hematologi

: Analis Pelaksana

\section{PEMBAHASAN}

Upaya peningkatan mutu mutu hasil laboratorium antara lain dengan pengendalian mutu internal, pengendalian mutu eksternal dan akreditasi Laboratorium (Kahar,2005). Lanoratorium RSUD Sultan Imanuddin telah terakreditasi tahun 2010. Dalam penilaian akreditasi ada beberapa standar yang dinilai diantaranya tujuan, visi dan misi laboratorium, kelengkapan organisasi, ketenegaan, fasilitas dan peralatan, prosedur kerja, pendidikan dan pelatihan mutu (PMI dan PME)

RSUD Sultan Imanuddin merupakan rumah sakit tipe $B$ non pendidikan. Secara kelengkapan organisasi sudah sesuai persyaratab yaitu mempunyai kepala instalasi laboratorium, koordinator laboratorium, penanggung jawab masing-masing bagian. Jumlah seluruh tenaga sebanyak 31 orang dimana sudah ada pembagian tugas, wewenang, dan tanggung jawab yang jelas sesuai kualifikasi pendidikan yang dimiliki. Pada dasarnya kegiatan laboratorium kesehatan harus dilakukan oleh petugas yang memiliki kualifikasi dan pengalaman yang memadai serta memperoleh kewenangan untuk melaksanakan kegiatan dibidang yang menjadi tugas atau tanggung jawabnya (Depkes, 2004).

Analisis Pelaksanaan Pemantapan Mutu Internal pemeriksaan $\underline{\text { Trombosit }}$

Dari hasil observasi yang diolah dengan statistic deskriptif berdasarkan skoring, diperoleh hasil seperti pada tabel 4,5, dan 6 . Penentuan criteria dibagi menjadi tiga kelompok sebagai berikut: criteria baik dengan persentase pencapaian 74-100\%; kriteria kurang baik dengan persentase pencapaian 60-74,9\%; kriteria tidak baik dengan criteria pencapaian $0-59,9 \%$ (Cahyono, 2008)

a. Tahap Pra Analitik 


\begin{abstract}
Pelaksanaan pemantapan mutu internal pemeriksaan trombosit di instalasi laboratorium klinik RSUD Sultan Imanuddin pada tahap pra analitik termasuk dalam kriteria baik dengan pencapaian $75,8 \%$. Pelaksanaan pemantapan mutu internal pemeriksaan trombosit tahap pra analitik berdasarkan observasi adalah sebagai berikut:

1) Identifikasi pasien dan spesimen
\end{abstract}

Kegiatan Identifikasi pasien dan spesimen sebenarnya sudah dilakukan dengan baik, namun ada beberapa item kegiatan yang perlu ditingkatkan pelaksanaanya, yaitu kelengkapan pengisian formulir permintaan laboratorium, penulisan tanggal pengambilan spesimen pada lebel di wadah spesimen, menolak spesimen yang tidak sesuai isi formulir permintaan pemeriksaan, menolak spesimen dengan identitas yang tidak lengkap, Berdasarkan hasil pengamatan, pengisian formulir permintaan laboratorium dari poliklinik biasanya hanya nama dan nomor transaksi yang terisi. Berdasarkan hasil wawancara dengan penanggung jawab laboratorium dan koordinator laboratorium, membenarkan hal tersebut sering terjadi, tetapi hal ini dapat diatasi dengan adanya SIM-RS. Dengan memasukkan nomor transaksi pasien maka semua data pasien akan muncul.

Data keterangan klinik pasien jarang sekali terisi tetapi jika ada hasil yang meragukan langsung dikonfirmasi dengan dokter pengirim melalui telefon. Pengisian identitas pada formulir permintaan pemeriksaan laboratorium yang tidak lengkap dapat mengakibatkan kesalahan pemeriksaan dan interpretasi hasil.

Sistem penomoran masih menggunakan cara manual sehingga untuk penulisan tanggal pada lebel spesimen dianggap tidak perlu karena 
merepotkan, selain itu sistem "One Day Service" yaitu hasil dapat dikeluarkan pada hari yang sama, sehingga kepentingan penambahan tanggal untuk label spesimen diabaikan.

2) Persiapan Pasien

Kegiatan persiapan pasien dalam kategori tidak baik, karena ada beberapa item yang jarang dilakukan, seperti memberikan informasi kepada pasien mengenai tindakan yang dilakukan, petugas biasanya mempersilah duduk dan langsung melakukan sampling tanpa memberikan informasi tindakan yang akan dilakukan. Selain itu berdasarkan hasil wawancara diketahui bahwa petugas hanya bertanya tentang obat yang diminum pasien untuk pemeriksaan glukosa saja, pasien dengan pemeriksaan yang lain jarang sekali bahkan tidak pernah ditanyakan. Informasi tentang obatobatan yang dikonsumsi oleh pasien penting untuk diketahui karena pada beberapa parameter dapat mempengaruhi hasil, sehingga interpretasi mungkin saja dapat berubah (Budiyono,2011).

3) Pengambilan Spesimen Kegiatan pengambilan spesimen di instalasi laboratorium RSUD Sultan Imanuddin dari hasil pengamatan peneliti sudah menggunakan peralatan dan wadah yang memenuhi persyaratan. Petugas telah memenuhi prosedur pengambilan spesimen.

Berdasarkan pencermatan dokumen petugas tidak selalu mencantumkan jam pengambilan spesimen pada formulir untuk pemeriksaan yang diambil di laboratorium.

Berdasarkan wawancara dengan petugas pengambilan specimen di laboratorium disamakan dengan jam order atau jam pendaftaran pasien yang ada di SIM-RS karena perbedaanya tidak terlalu bermakna yaitu hanya hitungan menit. 
4) Penanganan Spesimen

Kegiatan penanganan

spesimen

untuk

pemeriksaan trombosit

sudah baik.

\section{KESIMPULAN DAN SARAN}

1. Pelaksanaan pemantapan mutu internal untuk pemeriksaan darah lengkap otomatis di Instalasi Patologi Klinik RSUD Sultan Imanuddin Pangkalan Bun adalah:

b. Tahap analitik mencapai $76,4 \%$ masuk dalam kriteria kurang baik.
c. Tahap pasca analitik mencapai 69,2\% masuk dalam kriteria kurang baik.

2. Uji ketepatan, ketelitian, dan sigma metri untuk pemeriksaan trombosit adalah:

a. Ketepatan pemeriksaan trombosit di Instalasi Laboratorium RSUD Sultan Imanuddin kurang baik menurut acuan Ricos Database.

b. Ketelitian pemeriksaan trombosit di Instalasi
Laboratorium RSUD Sultan Imanuddin kurang baik menurut acuan Ricos Database.

\section{DAFTAR PUSTAKA}

Cohyono, Irveta Kania. 2008. Evaluasi Mutu Pelayanan Instalasi Laboratorium RSU Kasih Ibu Surakarta. Program Studi Ilmu Kesehatan Masyarakat. Universitas Gadjah Mada. Yogyakarta.

Depkes RI. 2004. Pedoman Praktek Laboratorium Yang Benar (Good Laboratory Practice). Cetakan 3. Direktorat Laboratorium Kesehatan. Direktorat Jenderal Pelayanan Medik Departemen Kesehatan RI. Jakarta.

Depkes RI. 2010. Pemantapan Mutu Eksternal Hematologi. Diunduh tanggal 28 Oktober 2011

Depkes RI. 1997. Petunjuk Pemantapan Mutu Internal Laboratorium Kesehatan. Direktorat Laboratorium Kesehatan. Direktorat Jenderal Pelayanan Medik Departemen Kesehatan Republik Indonesia. Jakarta.

Hadi, Anwar. 2000. Sistem Manajemen Mutu Laboratorium Sesuai ISO/IEC 17025: 2000. PT. 
Gramedia Pustaka Utama. Jakarta.

Hasmara, B, 2000. Studi Deskriptif tentang Manajemen Quality Assurance pada pelayanan Laboratorium di IPK RSUP Dr Kariadi Semarang. Universitas Diponegoro. Semarang.

Hoffbrand.1999. Kapita Selekta

Hematology. Edisi 4. EGC

Penerbit Buku Kedokteran.

Jakarta

Budiwiyono, Imam. 2011. Pengelolaan

Tahapan Pemeriksaan di Laboratorium

Klinik. Badan Penerbit

Universitas Diponegoro. Semarang.

Kahar, H. 2005. Mutu Pemeriksaan Di Laboratorium Klinik Rumah Sakit. Indonesian Journal Of Clinical Phatology and Medical Laboratory. 12 (1) 38-40.

Kanagasabapathy, A, \& Kmari, S. 2000. Guidelines on Standard Operating Prosedures for Clinical Chemistry. WHOSEARO. New Delhi

Kepmenkes RI No 828

/MENKES/SK/IX/2008. Tentang Petunjuk Teknis Standar Pelayanan Minimal Bidang Kesehatan di Kabupaten/Kota.

Kosasih, E.N, A.S. Kosasih. 2008.

Tafsiran Hasil Pemeriksaan Laboratorium Klinik.

Karisma publishing Group. Jakarta

Muslim, Muhamad. 2001. Pemantapan Mutu Dan Mutu Hasil Analisis Laboratorium Klinik Swasta Di Kalimantan Selatan. Program Studi Ilmu
Kesehatan Masyarakat.

Universitas Gadjah Mada. Yogyakarta.

Mehta, Hoffbrand, 2008. At Glance

Hematology. Edisi 2. Penerbit Erlangga. Jakarta

Moleong, 2010. Metodologi Penelitian Kualitatif. Penerbit PT Remaja Rosda Karya. Bandung.

Profil Rumah Sakit Umum Daerah Penembahan Senopati Sultan Imanuddin Kota Yogyakarta. 2010.

Pusorowati, Nunuk. 2004. Konsep Dasar Upaya Peningkatan Mutu Pelayanan Rumah Sakit. Clinical Epidemiology and Biostatistic unit RSUP Dr Sardjito/ FK-UGM Yogyakarta.

Setiabudy, Rahajuningsih. 2007. Hemostasis dan Trombosit. FKUI Jakarta

Siregar, Charles J. 2007. Praktik Sistem Manajemen Laboratorium Pengujian Yang Baik. EGC Penerbit Buku Kedokteran. Jakarta.

Speicher, Carl E. dan Smith, Jr., Jack W. 1994. Pemilihan Uji Laboratorium Yang Efektif. EGC Penerbit Buku Kedokteran. Jakarta.

Sugiyono. 2009. Metode Penelitian Kuantitatif, Kualitatif dan $R$ \& D. Cetakan 9. CV. Alfabeta. Jakarta. 
Sukorini, Usi, Nugroho, D. K., Rizki, M.,

Hendriawan P. J., B. 2010.

Pemantapan Mutu Internal

Laboratorium Klinik.

Kanalmedika dan Alfamedia

Citra. Yogyakarta.

Van Dun, L, 2007. Quality Control. Abbot Hematology.

Widmann, Frances K. 1994. Tinjauan

Klinis Atas Hasil

Pemeriksaan Laboratorium.

Edisi 9. EGC Penerbit Buku

Kedokteran. Jakarta.

Westgard, J., 2010. Westgard Rules and Multirules. Di unduh pada tanggal 22 Oktober 2011 dari http://www.westgard.com.

Westgard, J., 2009. Desirable Specifications For Total Error, Imprecision and Bias, Derived From Intra And Inter Individual Biologic Variation. Diunduh tanggal 22 Oktober 20011 dari http://www.westgard.com 